\title{
On a new dynamomagnetic phenomenon
}

\section{Trève \& Durassier}

To cite this article: MM. Trève \& Durassier (1876) On a new dynamomagnetic phenomenon, Philosophical Magazine Series 5, 2:14, 549-550, DOI: 10.1080/14786447608639150

To link to this article: http://dx.doi.org/10.1080/14786447608639150

$$
\text { 曲 Published online: } 13 \text { May } 2009 .
$$

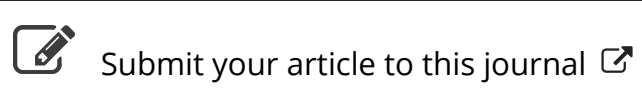

\footnotetext{
Џ Article views: 2
}

Q View related articles $\asymp$ 


\section{$\left[\begin{array}{lll}549 & \end{array}\right]$}

LXVII. Intelligence and Miscellaneous Articles.

\section{ON A NEW DYNAMOMAGNETIC PHENOMENON. BX MM. TRÈVE AND DURASSIER.}

IET a horse-shoe magnet of any length be covered on one face with varnish, or, better, with a strip of glass. If a cylinder of soft iron be placed upon its neutral part, the cylinder will begin to move toward the poles, which it reaches in a time which is of course a function of the weight of the cylinder and the coercive force of the magnet.

The magnetic attraction, therefore, is here exerted, not in the limited field which has been recognized for it, but over the whole extent of the magnet.

Hence results a new mode of valuing magnetic force, by the mechanical work which it has performed. The product of the weight of the iron moved, multiplied by the space passed through, divided by the time elapsed, will be the precise measure of this magnetic force. If, for example, the force be determined for three large and three small magnets, identical in shape and weight, and containing respectively $0.25,0.5$, and 1 per cent. of carbon, it will perhaps be possible to define the unit of magnetic force ("the magnety"), and fix its equivalence in kilogrammetres.

We had made great efforts to determine the magnetic conductivity of steels in proportion to their content of carbon; but the want of a rigorous mode of valuation of magnetic forces had always prevented us. The phenomenon above described will fill the gap and permit us to accomplish this important purpose. We must here, however, indicate the course we have followed.

If, for instance, a steel with 1 per cent. carbon be taken, of our first series of Creusot, it is known that its coercive force is approximately 47 degrees on the compass.

Let us place it in an induction-coil, like an ordinary electromagnet, giving to the coil the proportions of length, section, wire, \&c. fixed by the formulæ of M. du Moncel for the purpose of obtaining a maximum of magnetic power, and send through it a strong current in the wished-for direction. Under these conditions the magnet gives no longer 47 , but 64 degrees. If 47 and 64 were absolute numbers, one could say that the magnet $A_{1}$ bas 47 of permanent magnetism, but can take 64 in the temporary state. 64 would represent the magnetic capacity of the magnet with 1 per cent. carbon-that is to say, the maximum of magnetism which it is capable of rece'ving. The difference between 64 and 47 would give the magnetic conductivity.

Now let the extreme steel of the series be $\mathrm{E}_{3}$ with 0.25 per cent. of carbon. Its coercive force is 13 . If to it be applied the same coil ss to $A_{1}$, since they are identical in form and weight, its magnetic capacity is found to be 69 . The difference between 69 and 13 would be the magnetic conductivity of the steel with 0.25 per cent. of carbon. 
We have operated in the same manner for $B_{1}, C_{1}, D_{1}$, and have drawn up the following Table:-

\begin{tabular}{|c|c|c|c|}
\hline & Coe & re Force. & Magnetic Oapacity. \\
\hline$A_{1}$ & $\ldots \ldots \ldots$ & 47 & 64 \\
\hline$B_{1}$ & $\cdots$ & 45 & 66 \\
\hline $\mathrm{C}_{1}$ & $\ldots \ldots$ & $42 \cdot 5$ & 67 \\
\hline$D_{1}^{2}$ & $\ldots \ldots$ & $33 \cdot 5$ & 68 \\
\hline $\mathrm{E}_{1}^{2}$ & $\ldots \ldots \ldots$ & 13 & 69 \\
\hline
\end{tabular}

The magnetic capacity of soft iron of the same form and weight was 71 .

These approximate relations show how important it was to seek out a method of rigorous measurement of magnetic power.Comptes Rendus de l'Académie des Sciences, Nov. 9, 1876, tome lxxxiii. pp. 857,858 .

ON SOME REMARKABLE PHENOMENA IN GEISSLER TUBES. BY PROF. E. REITLINGER AND A. VON URBANITZKY.

Having, at the commencement of July last, made preparation for continuing our experiments with the aid of a Geissler mercury air-pump, we filled so-called $W$ üllner tubes with different gases, and first investigated afresh the conversion of attraction into repulsion by a higher degree of rarefaction. The experiments were made with air, nitrogen, oxygen, hydrogen, and carbonic acid. They established that, with all these gases, between 4 and 12 millims. pressure the electrical luminous column is attracted, but at about 2-1 millim. it is repelled. Between the two phenomena there is an intermediate stage, in which neither attraction nor repulsion is perceptible. For the first occurrence, however, of perceptible repulsion it was the less possible to find with the different gases one and the same degree of rarefaction, as the repulsion and attraction proved to be dependent on the intensity of the current, and, for example, a luminous column which showed itself indifferent to the finger was caused distinctly to recede from the finger by the insertion of a resistance. Now since the gases in the tube themselves offer different degrees of resistance, we had to take into account at the same time the intensity of the current, in order to render the data comparable. The latter bas been found to exert the greatest influence; yet up to the present time we have only numerous results to communicate at the proper time respecting that influence, but have ascertained no general law for it: this we shall endeavour to discover. If rarefaction be continued below 1 millim., in all the cases which we have observed, layers are produced as the rarefaction proceeds, of little breadth and constant in position so far as our observation extends, which either do not retreat before the finger at all, or only when the induction-current is very much weakened by the insertion of resistances. In consequence of this circumstance the repulsion exhibits a certain maximum during the rarefaction, which again diminishes when the rarefaction is carried still further. A portion of the experiments were made with a somewhat wider tube without any capillary part, which thus was in a certain sense intermediate between the Geissler 